\title{
Mechanical Behavior and Reliability of Anchoring Resin under Thermomechanical Coupling
}

\author{
Wentang Wang ${ }^{1 *}$, Baoyan Feng ${ }^{2}$ \\ ${ }^{1}$ College of Mechanical Engineering, Henan Institute of Technology, Xinxiang 453003, China \\ ${ }^{2}$ Management Committee of Xinxiang Test Base, Chinese Academy of Agricultural Sciences, Xinxiang 453731, China
}

Corresponding Author Email: awentang@126.com

https://doi.org/10.18280/ijht.370212

Received: 8 January 2019

Accepted: 12 April 2019

\section{Keywords:}

thermomechanical coupling, anchoring resin, mechanical performance, tensile shear strength, Rheological performance

\begin{abstract}
This paper attempts to disclose the mechanical behavior and deformation performance of the resin anchor of the roadway in high temperature, deep mines, under the coupling between stress and temperature. Drawing on the relevant theories on thermomechanical coupling, this paper tests the strength, elastic modulus, Poisson's ratio and rheological performance of the anchoring resin under thermomechanical coupling, and compares the pull-out and rheological performances of the resin anchored layer under different temperatures and stresses. The results show that: With the increase in test temperature, the anchoring resin witnessed a gradual decline in its compressive strength and yield stress, a continuous decrease of its elastic modulus, a gradual growth in the Poisson's ratio, and a reduction in the yield point; The rheological deformation of the anchoring resin is affected by test temperature and stress; There is a negative correlation between the ambient temperature and the pull-out force needed to displace the anchoring resin by a certain distance, under the high temperature environment; In high-temperature, deep mines, anchoring resin is significantly affected by the ambient temperature and stress. The research findings lay the theoretical basis for the advancement of roadway support technique in deep mines under thermomechanical coupling.
\end{abstract}

\section{INTRODUCTION}

The roadways in deep coalmines should be effectively reinforced due to the high geo-stress and temperature [1-2]. In recent years, rock anchoring has become increasingly popular in roadway excavation and reinforcement, thanks to its strong ability to improve the stress state on roadway surface. Engineering practice has shown that rock bolting is more effective in enhancing roadways than metal support, wood support and joint support [3-4]. Being the most widely used mode of rock anchoring, resin anchoring embeds the anchor into the surrounding rock of the roadway, and bonds it with the rock by unsaturated polyester [4-9]. Compared with cement mortar and other rock anchoring materials, the resin material solidifies fast, realizes efficient support, and facilitates construction [10-12].

The stress state of the anchor in deep mines differs greatly from that in shallow mines. Thus, the resin anchoring system, consisting of the anchor, the resin anchored layer and the surrounding rock, in deep mines must have vastly different mechanical features from that in shallow mines [13-14]. The supporting effect of the rock anchoring system hinges on the mechanical reliability of the resin anchored layer [15]. The existing studies have probed deep into the stress features of the anchor under load, but rarely examined the mechanical features of the anchoring material and the anchored layer under the coupling between temperature and load [16]. Therefore, it is of great theoretical and practical significance to explore the mechanical features and reliability of rock bolting system in coalmines under thermomechanical coupling.
Drawing on the relevant theories on thermomechanical coupling, this paper explores the deformation features and basic mechanical performance of the resin anchor and the anchored layer under the coupling between the stress field and the temperature field. The resin anchoring system of the roadway in a deep coalmine was selected as the object of the test. Next, the mechanical performances of the anchoring resin were compared under different temperatures, and the attenuation law of the anchoring performance with temperature was characterized.

\section{SPECIMEN PREPARATION AND TEST PLAN}

\subsection{Specimen preparation}

The research object is the unsaturated polyester used to anchor the roadway in a coalmine. The performance parameters of the material are listed in Table 1.

Cylindrical specimens (diameter: $50 \mathrm{~mm}$; height: $100 \mathrm{~mm}$ ) were prepared to test the performance parameters of the resin anchor, including elastic modulus, compressive strength and Poisson's ratio. Through the following steps, the uniaxial compressive strength and deformation features of the resin anchor were measured under different temperatures: the specimen was heated up to the test temperature at the preset rate; the test temperature was maintained for $1 \mathrm{~h}$; the uniaxial compression was performed by the MTS 810 test machine; the vertical displacement, hoop strain and other parameters of the specimen were recorded. 
Table 1. Performance parameters of the anchoring resin

\begin{tabular}{ccccccc}
\hline Type & $\begin{array}{c}\text { Gel } \\
\text { time/s }\end{array}$ & Mixing time /s & $\begin{array}{c}\text { Bearing } \\
\text { time/min }\end{array}$ & $\begin{array}{c}\text { Compressive strength } \\
/ \mathbf{M P a}\end{array}$ & $\begin{array}{c}\text { Shear strength } \\
/ \mathbf{M P a}\end{array}$ & $\begin{array}{c}\text { Elastic modulus } \\
/ \mathbf{M P a}\end{array}$ \\
\hline $\mathrm{Z}$ & $90-170$ & $30-40$ & 30 & $1.15 \times 10^{4}$ & $\geq 40$ & $\geq 36$ \\
\hline
\end{tabular}

The vertical strain $\varepsilon_{L}$, elastic modulus $E_{\mathrm{av}}$ and Poisson's ratio $\mu$ can be calculated respectively by:

$$
\begin{gathered}
\varepsilon_{\mathrm{L}}=\frac{\Delta L}{L_{0}} \\
E_{a v}=\Delta \sigma / \Delta \varepsilon_{L} \\
\mu=\frac{\varepsilon_{c}}{\varepsilon_{L}}
\end{gathered}
$$

where, $\Delta L$ is the increment of vertical displacement of the specimen; $L_{0}$ is the original length of the specimen; $\Delta \sigma$ and $\Delta \varepsilon_{L}$ are the stress increment and strain increment in a section of the straight segment on the stress-strain curve, respectively; $\varepsilon_{\mathrm{c}}$ and $\varepsilon_{L}$ are the vertical strain and hoop strain at the end of the straight segment on the vertical strain-hoop strain curve, respectively.

\subsection{Test parameters}

To disclose the strength and deformation features of the anchoring resin, the specimens were heated up at a specific rate $\left(0.3 \sim 0.5{ }^{\circ} \mathrm{C} / \mathrm{min}\right)$ to $26{ }^{\circ} \mathrm{C}, 40{ }^{\circ} \mathrm{C}, 60{ }^{\circ} \mathrm{C}$ and $80{ }^{\circ} \mathrm{C}$, respectively, and maintained at the corresponding temperatures for more than $1 \mathrm{~h}$. After that, the specimens were loaded at $0.3 \mathrm{MPa} / \mathrm{s}$ until destructed. Each specimen was tested six times under each temperature. The strain, displacement and load were recorded. The mean value of each type of data was taken after eliminating errors.

The rheological performance of the anchoring resin was determined based on the time-variation in the deformation of resin anchor specimens which entered the rheological state under the constant pressure of $10 \mathrm{MPa}$ and $20 \mathrm{MPa}$, respectively.

\subsection{Test procedures}

A total of 24 tensile shear specimens were prepared to test the tensile shear performance of the anchoring resin. As shown in Figure 1, each specimen has a steel cylinder (diameter: 24 $\mathrm{mm}$ ) that simulates the borehole in the surrounding rock, and a ribbed bar (nominal diameter: $11 \mathrm{~mm}$ ) that simulates the anchor. The bar and anchor were bonded for a length of $50 \mathrm{~mm}$. The prepared specimens were cured for more than $3 \mathrm{~d}$ in the curing box (temperature: $22{ }^{\circ} \mathrm{C}$; humidity: $65 \%$ ), and then subjected to tensile shear tests under different temperatures in the MTS810 test machine.

The 24 specimens were divided equally into four groups, which were subjected to pull-out tests under different temperatures $\left(26{ }^{\circ} \mathrm{C}, 40{ }^{\circ} \mathrm{C}, 60{ }^{\circ} \mathrm{C}\right.$ and $\left.80{ }^{\circ} \mathrm{C}\right)$. For each test, the environmental box of the test machine was adjusted to the test temperature; next, the specimen was placed into the machine, and the test temperature was maintained for $2 \mathrm{~h}$; after that, the specimen was loaded at $0.0625 \mathrm{~mm} / \mathrm{s}$; the loaddisplacement curve and related data were recorded. Among them, the ultimate pulling resistance $F_{\max }$ of each specimen can be computed by:

$$
F_{\max }=\frac{F \cdot L_{0}}{L}
$$

The pull-out performance of the resin anchored layer under the rheological state was tested in two phases. In phase one, the test was conducted at a small, constant load (such as the specimen was under elastic tensioning); in phase two, the specimen was heated up to $80{ }^{\circ} \mathrm{C}$ at $1{ }^{\circ} \mathrm{C} / \mathrm{min}$ to test the tensile shear performance under the rheological state. Three specimens were tested in each phase.

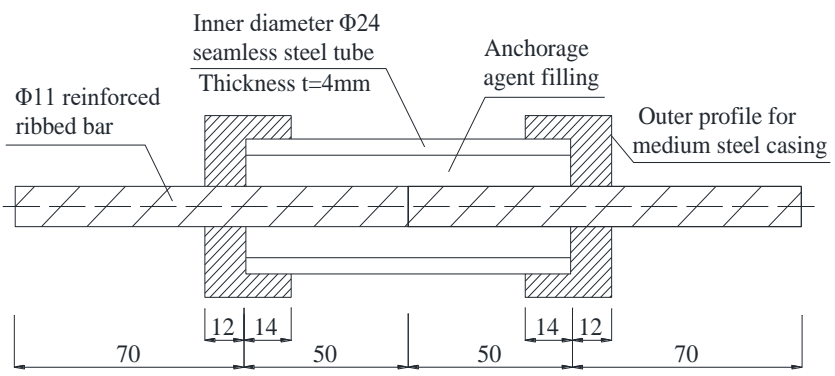

Figure 1. Design parameters of specimens

\section{MECHANICAL PERFORMANCE OF ANCHORING RESIN}

\subsection{Tensile shear strength}

Figure 2 describes the relationship curves between the load $\mathrm{F}$ on the anchoring resin and the pull-out displacement $\mathrm{s}$ of the anchoring resin at different temperatures $\left(\mathrm{A}: 26{ }^{\circ} \mathrm{C}\right.$; B: $40{ }^{\circ} \mathrm{C}$; C: $60^{\circ} \mathrm{C}$; D: $80^{\circ} \mathrm{C}$ ). It can be seen that the load-displacement curves could be divided into four segments: the first segment (the shear elastic segment) saw the load grow linearly with the increase in displacement; the second segment (the plastic shear segment) saw the load grow nonlinearly to the peak value with the increase in displacement; the third segment (the initial shear failure segment) saw the load gradually decline with the increase in displacement; the fourth segment (the massive shear failure segment) saw the load varied slightly despite the increase in displacement.

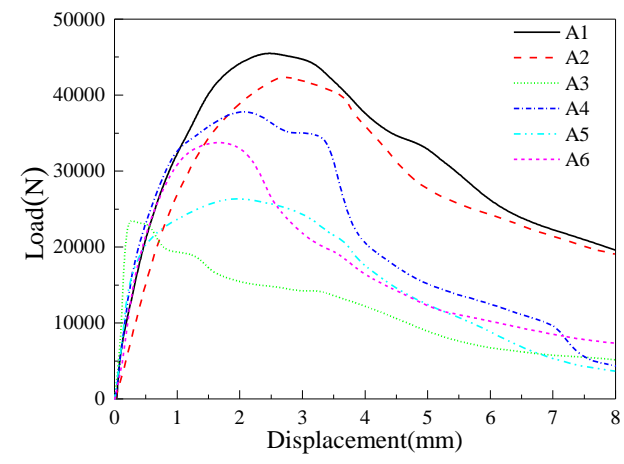

(a) $26^{\circ} \mathrm{C}$ 


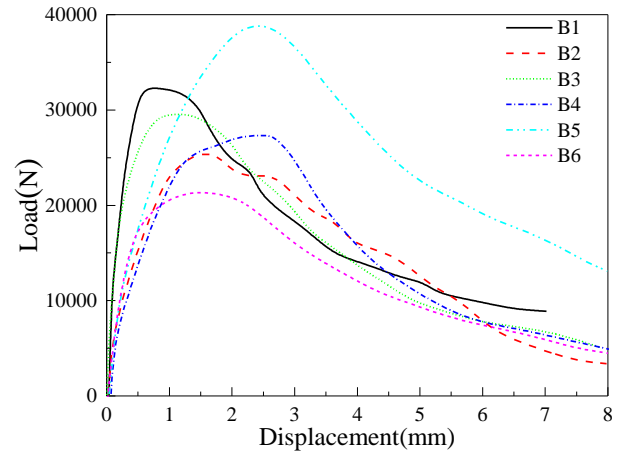

(b) $40{ }^{\circ} \mathrm{C}$

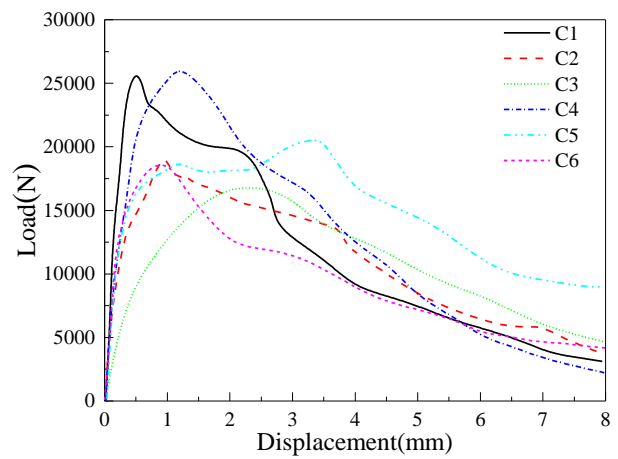

(c) $60{ }^{\circ} \mathrm{C}$

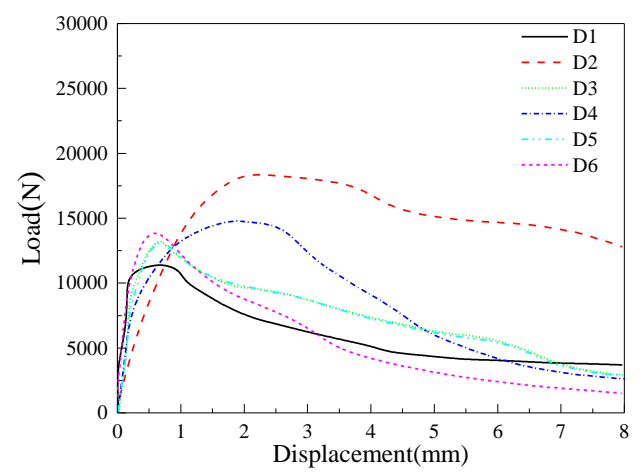

(d) $80^{\circ} \mathrm{C}$

Figure 2. Load-displacement curves at different temperatures

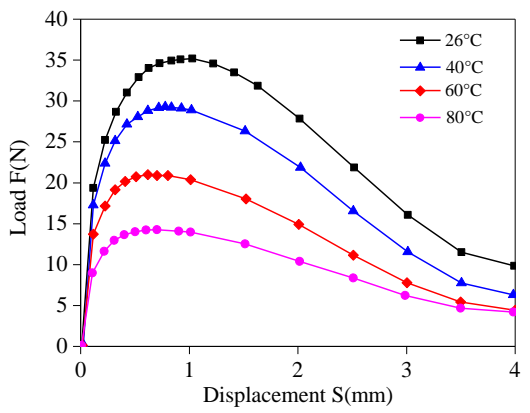

Figure 3. Pull-out load-displacement curves at different temperatures

In each pull-out test, the pull-out load was symmetric about the centerline of the anchoring resin. Therefore, the specimen displacement measured in each test was divided by two to obtain the pull-out load-displacement curves at the corresponding temperature (Figure 3). It can be seen that, when the pull-out displacement was $0.5 \mathrm{~mm}$, the pull-out forces were $33.7,27.4$ and $21.3 \mathrm{kN}$, respectively, in the three test environments. Hence, there is a negative correlation between the ambient temperature and the pull-out force needed to displace the anchoring resin by a certain distance, under the high temperature environment.

\subsection{Rheological performance}

In the first set of tests, the resin anchor was loaded at $5 \mathrm{~mm} / \mathrm{min}$ to $5 \mathrm{kN}$ under $26{ }^{\circ} \mathrm{C}$, the pressure was then maintained for $1.5 \mathrm{~h}$, and the time variation in pull-out displacement of the resin anchor was recorded as Figure 4. Under the pull-out force of $5 \mathrm{kN}$, the mean instantaneous displacement of the resin anchor was about $2 \mathrm{~mm}$. During the 1h-long test period, the pull-out displacements of the three specimens respectively increased by $0.06-0.16 \mathrm{~mm}$, about 30 - $80 \%$ greater than the corresponding instantaneous displacements.

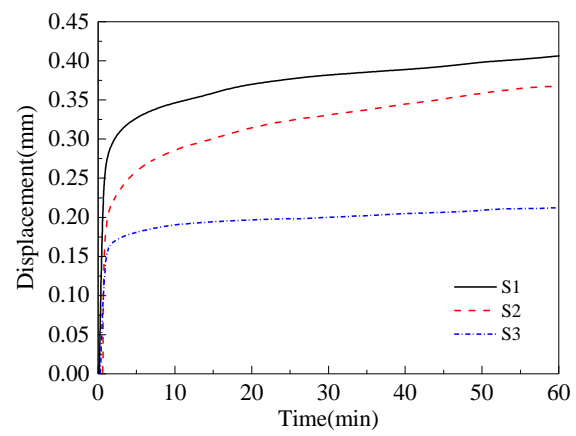

Figure 4. Pull-out displacement-time curves at $26{ }^{\circ} \mathrm{C}$

In the second set of tests, the resin anchor was loaded at 5 $\mathrm{mm} / \mathrm{min}$ to $5 \mathrm{kN}$ under $26^{\circ} \mathrm{C}$, and then heated up at $1{ }^{\circ} \mathrm{C} / \mathrm{min}$ to $80{ }^{\circ} \mathrm{C}$. The time variation in pull-out displacement of the resin anchor was recorded as Figure 5. It can be seen that the pull-out displacement of the resin anchor grew rapidly with the elapse of time. Specimen 3 suffered from debonding failure after the rheological displacement surpassed $1 \mathrm{~mm}$.

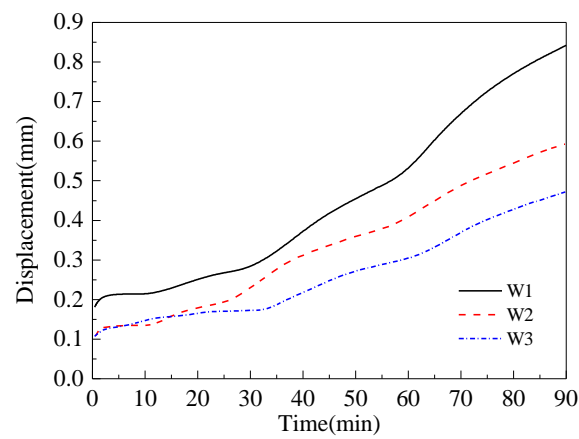

Figure 5. Pull-out displacement-time curve in heating process

Next, the ANSYS finite-element software was adopted to create a 1:2 scale model based on the above tests, and used to study the correlation between the rheological performance of the resin anchored layer and the displacement of the resin anchor. The finite-element simulation was carried out at the ambient temperature of $26{ }^{\circ} \mathrm{C}$. Figure 6 displays the time variation in the displacement between the resin anchor and the resin anchored layer at different anchoring depths and at $40 \mathrm{~min}$ into the rheological state. It can be seen that the 
rheological displacement of the resin anchored layer was obviously smaller at the anchor bottom than at the anchor end, and that the pull-out displacement of the resin anchor was greatly affected by the rheological features of the resin anchored layer. Thus, the finite-element simulation outputted similar results with the above tests.

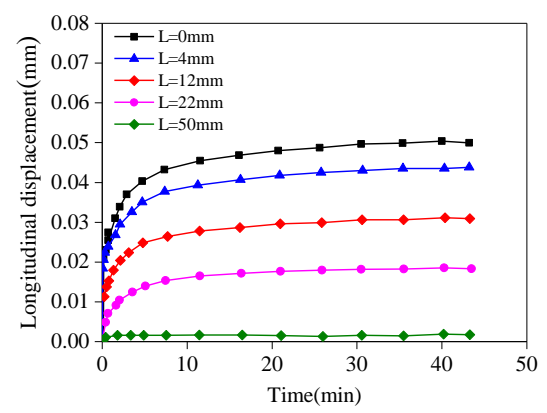

Figure 6. Time variation in the displacement between resin anchor and resin anchored layer at different anchoring depths

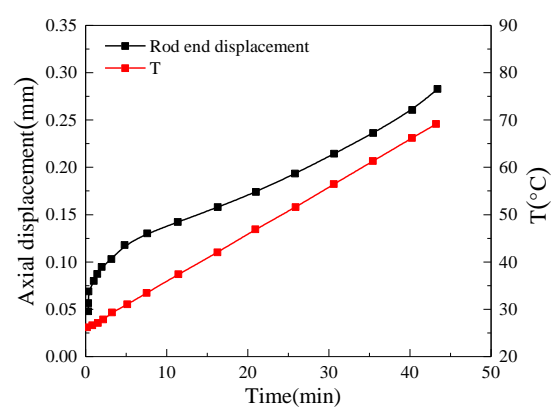

Figure 7. Time variation of the anchor end displacement at $26^{\circ} \mathrm{C}$

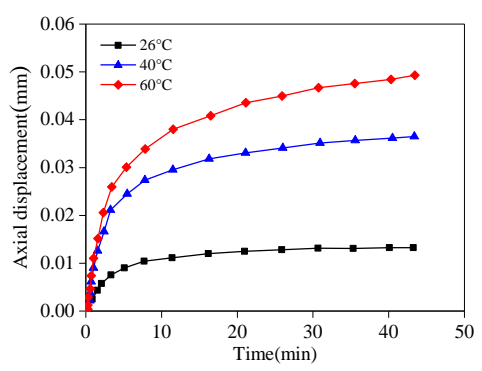

Figure 8. Time variation in anchor end displacement at different temperatures

Next, the heating rate of the model was set to $1 \mathrm{~min} /{ }^{\circ} \mathrm{C}$ in the finite-element software. Under this condition, the time variation of the anchor end displacement was computed for the rheological state under constant load and rising temperature, and plotted as Figure 7. Comparing Figure 7 and Figure 5, it is learned that the finite-element simulation produced basically the same results with the above tests, under the thermomechanical coupling. As a result, the pull-out displacement of the resin anchor must be affected by the thermodynamic performance of the material. Figure 8 illustrates the time variation in anchor end displacement at different temperatures. It can be seen that the anchor end displaced much faster under high temperature than under $26^{\circ} \mathrm{C}$; After being applied with a constant load for $45 \mathrm{~min}$, the resin anchor's rheological displacement increment under
$40{ }^{\circ} \mathrm{C}$ was twice that under $26^{\circ} \mathrm{C}$. The results show that, in high-temperature, deep mines, anchoring resin is under the joint impacts of the thermodynamic performance of the material and the ambient temperature.

\section{CONCLUSIONS}

Targeting the resin anchoring system of the roadway in a deep coalmine, this paper carries out tests and numerical simulations on the strength and deformation features of the anchoring resin, as well as the rheological and pull-out performance of the resin anchored layer, under the thermomechanical coupling. The main conclusions are as follows:

(1) With the increase in test temperature, the anchoring resin witnessed a gradual decline in its compressive strength and yield stress, a continuous decrease of its elastic modulus, a gradual growth in the Poisson's ratio, and a reduction in the yield point.

(2) The rheological deformation of the anchoring resin is affected by test temperature and stress. Under the thermomechanical coupling, the rheological deformation of the material picked up speed from the stable state, when the load or temperature exceeded a certain limit. The higher the temperature, the greater the test stress, and the more obvious the plastic deformation of the anchoring resin.

(3) There is a negative correlation between the ambient temperature and the pull-out force needed to displace the anchoring resin by a certain distance, under the high temperature environment. In high-temperature, deep mines, anchoring resin is significantly affected by the ambient temperature and stress.

\section{REFERENCES}

[1] Ngo, M., Ibrahimbegovic, A., Brancherie, D. (2013). Continuum damage model for thermo-mechanical coupling in quasi-brittle materials. Engineering Structures, $\quad 50$ : 170-178. http://doi.org/10.1016/j.engstruct.2012.10.007

[2] Yang, Z.H., Cui, J.Z., Nie, Y.F., Huang, Z.Q., Xiang, M.Z. (2015). Dynamic thermo-mechanical coupled simulation of statistically inhomogeneous materials by statistical second-order two-scale method. Acta Mechanica $\quad$ Sinica, 31(5): 762-776. http://doi.org/10.1007/s10409-015-0483-9

[3] Ngo, M., Brancherie, D., Ibrahimbegovic, A. (2014). Softening behavior of quasi-brittle material under full thermo-mechanical coupling condition: theoretical formulation and finite element implementation. Computer Methods in Applied Mechanics and Engineering, 281: 1-28. http://doi.org/10.1016/j.cma.2014.07.029

[4] Chin, J., Forster, A., Ocel, J., Hartmann, J., Fuchs, P., Hunston, D. (2010). Thermo-viscoelastic analysis and creep testing of ambient temperature cure epoxies used in adhesive anchor applications. Journal of Materials in Civil Engineering, 22(10): 1039-1046. http://doi.org/10.1061/(asce)mt.1943-5533.0000108

[5] Chin, J., Forster, A., Clerici, C., Hunston, D. (2010). Characterization of ambient temperature cure epoxies used in adhesive anchor applications. The Journal of 
Adhesion,

$86(10)$

$27-27$

http://doi.org/10.1080/00218464.2010.515494

[6] Liebl, C., Lion, A. (2011). A one-dimensional approach to the chemical and thermos-mechanical coupled modeling of curing adhesives including plasticity. Pamm, 11(1): 405-406. http://doi.org/10.1002/pamm.201110194

[7] Fu, R., Weng, H., Wenk, J., Martin, A. (2015). Application of a new thermal-mechanical coupling solver for ablation. Aiaa Thermophysics Conference. http://doi.org/10.2514/6.2016-4432

[8] Zhang, Y.J., An, L.Q., Ma, N.J. (2011). Infrared changes in the progressive failure and stress distribution of bolted rocks. Advanced Materials Research, 337(4): 709-712. http://doi.org/10.4028/www.scientific.net/amr.

[9] Audebert, M., Dhima, D., Taazount, M., Boucha R, A. (2012). Behavior of dowelled and bolted steel-to-timber connections exposed to fire. Engineering Structures, 39: 116-125. http://doi.org/10.1016/j.engstruct.2012.02.010

[10] Santiuste, C., Barbero, E., María, H.M. (2011). Computational analysis of temperature effect in composite bolted joints for aeronautical applications. Journal of Reinforced Plastics \& Composites, 30(1): 311. http://doi.org/10.1177/0731684410385034

[11] Ahmad, H., Johnson, W.S., Counts, W.A. (2003). Evaluation of bolt bearing behavior of highly loaded composite joints at elevated temperature. Journal of $\begin{array}{lll}\text { Composite } \quad \text { 37terials, } & \text { 559-571. }\end{array}$ http://doi.org/10.1177/0021998303037006679
[12] Travassos, G.D., Rodrigues, L.F.A., de-Araújo, C.J. (2016). Fabrication and thermomechanical characterization of a new $\mathrm{Cu}-\mathrm{Al}-\mathrm{Ni}-\mathrm{Mn}-\mathrm{Ti}$ shape memory alloy bolt. Journal of the Brazilian Society of Mechanical Sciences \& Engineering, 39(4): 1-7. http://doi.org/10.1007/s40430-016-0617-4

[13] Ince, U., Güden, M. (2013). An iterative numerical method for determination of temperature-dependent friction coefficients in thermomechanical model analysis of cold bolt forging. International Journal of Advanced Manufacturing Technology, 68(9-12): 2133-2144. http://doi.org/10.1007/s00170-013-4831-2

[14] Zhou, W., Zhang, R., Ai, S., He, R., Pei, Y., Fang, D. (2015). Load distribution in threads of porous metalceramic functionally graded composite joints subjected to thermomechanical loading. Composite Structures, 134: 680-688.

http://doi.org/10.1016/j.compstruct.2015.08.113

[15] Pascual, A.M., Romero, M.L., Tizani, W. (2015). Fire performance of blind-bolted connections to concrete filled tubular columns in tension. Engineering Structures, 96:

111-125. http://doi.org/10.1016/j.engstruct.2015.03.067

[16] Zhang, Y.J., An, L.Q., Ma, N.J. (2011). Study on infrared characteristics in the progressive failure of bolted rocks under uniaxial compression. Advanced Materials Research, $332-334(5)$ : $1227-1231$ http://doi.org/10.4028/www.scientific.net/amr.332334.1227 